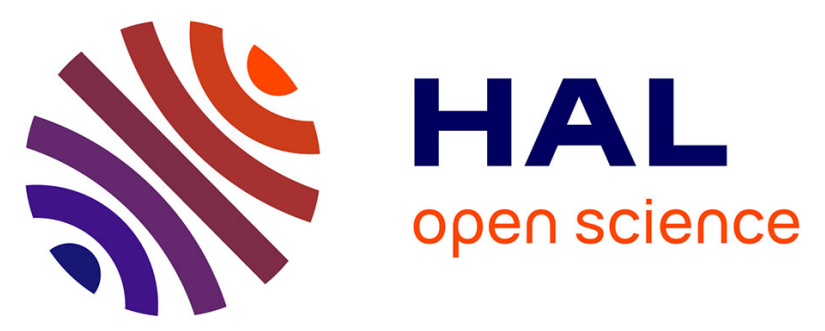

\title{
Mid-IR integrated cavity based on Ge-rich graded SiGe waveguides with lateral Bragg grating
}

Qiankun Liu, Joan Manel Ramírez, Vladyslav Vakarin, Jacopo Frigerio, Andrea Ballabio, Xavier Le Roux, Laurent Vivien, Carlos Alonso-Ramos, Giovanni Isella, Delphine Marris-Morini

\section{To cite this version:}

Qiankun Liu, Joan Manel Ramírez, Vladyslav Vakarin, Jacopo Frigerio, Andrea Ballabio, et al.. Mid-IR integrated cavity based on Ge-rich graded SiGe waveguides with lateral Bragg grating. OSA High-brightness Sources and Light-driven Interactions Congress (Mid-Infrared Coherent Sources MICS ), Mar 2018, Strasbourg, France. 10.1364/MICS.2018.MM3C.4 . hal-01798830v2

\section{HAL Id: hal-01798830 \\ https://hal.science/hal-01798830v2}

Submitted on 26 Jun 2020

HAL is a multi-disciplinary open access archive for the deposit and dissemination of scientific research documents, whether they are published or not. The documents may come from teaching and research institutions in France or abroad, or from public or private research centers.
L'archive ouverte pluridisciplinaire HAL, est destinée au dépôt et à la diffusion de documents scientifiques de niveau recherche, publiés ou non, émanant des établissements d'enseignement et de recherche français ou étrangers, des laboratoires publics ou privés. 


\title{
Mid-IR integrated cavity based on Ge-rich graded SiGe waveguides with lateral Bragg grating
}

\author{
Qiankun Liu $^{1}$, Joan Manel Ramírez ${ }^{1}$, Vladyslav Vakarin${ }^{1}$, Jacopo Frigerioº ${ }^{2}$, Andrea Ballabio ${ }^{2}$, \\ Xavier Le Roux ${ }^{1}$, Laurent Vivien ${ }^{1}$, Carlos Alonso-Ramos ${ }^{1}$, Giovanni Isella ${ }^{2}$, Delphine Marris-Morini ${ }^{1}$ \\ 1. Centre de Nanosciences et de Nanotechnologies, CNRS, Univ. Paris-Sud, Université Paris Saclay, C2N-Orsay, 91405 Orsay, France \\ 2. L-NESS, Dipartimento di Fisica, Politecnico di Milano, Polo di Como, Via Anzani 42, I 22100 Como, Italy \\ Authore-mail address: qiankun.liu@u-psud.fr
}

\begin{abstract}
We report the design of a Bragg-mirror based Fabry-Perot cavity integrated on SiGe waveguides working at $7.25 \mu \mathrm{m}$. The demonstration of such resonant structures will be a major step forward for sensing applications in mid-infrared.

OCIS codes: (130.0130) Integrated optics; (130.3120) Integrated optics devices
\end{abstract}

\section{Introduction}

Photonics integrated circuits (PICs) in the mid-infrared (MIR) have attracted a lot of interest, particularly for novel applications in medical diagnosis, chemical and biological sensing, free-space telecommunication or security [1]. The Ge-rich SiGe graded waveguides benefit from a wide transparent window, strong $3^{\text {rd }}$ order nonlinearity, broadband dispersion engineer-ability [2] and compatibility with silicon photonics. Such structures have revealed to be a promising platform to realize complex mid-infrared PICs in a wide wavelength range. For example broadband Mach Zehnder interferometers have been experimentally demonstrated from 5.5 to $8.5 \mu \mathrm{m}$ wavelength, working in both quasi-TE and TM polarizations [3]. However, some key devices are still required in order to demonstrate the full potential of this platform, among which resonant structures that will be crucial for sensing applications where strong light-matter interaction is desired. In this context, a Fabry-Perot cavity using lateral Bragg grating mirrors might be a promising option to develop mid-IR SiGe cavities with high performance. In this work we design Bragg grating mirror based on graded SiGe waveguide and evaluate the performances of integrated cavities around $7.25 \mu \mathrm{m}$.

\section{Design and simulation}

The waveguide design is based on a $6 \mu \mathrm{m}$-thick graded $\mathrm{Si}_{1-\mathrm{x}} \mathrm{Ge}_{\mathrm{x}}$ rib waveguide. As illustrated in Fig 1(a) the Bragg mirror is obtained by a lateral corrugation of the waveguide width, permitting simple fabrication using a single etching step to define simultaneously the waveguide and Bragg mirrors, with $1 \mu \mathrm{m}$ grating period, $4 \mu \mathrm{m}$ etching depth and with a duty cycle of 50\%. The mirror reflectivity at the central wavelength is up to $95 \%$, using a $200 \mu \mathrm{m}$-long grating, and the spectral bandwidth is $62 \mathrm{~nm}$. The transmission of a $600 \mu \mathrm{m}$-long cavity using these mirrors is plotted in Fig 1(b). Moreover, the theoretical Q-factor around $1 \times 10^{4}$ is expected assuming $1 \mathrm{~dB} / \mathrm{cm}$ propagation losses.

(a)

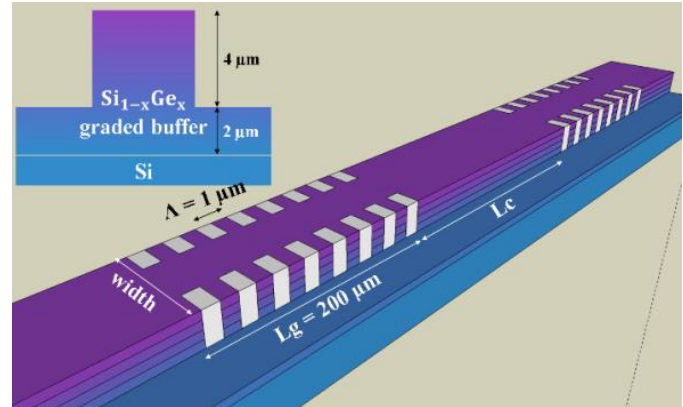

(b)

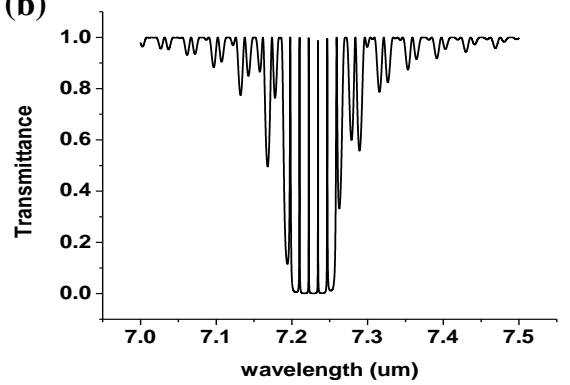

Fig. 1. (a) Schematic view of Fabry-Perot cavity with lateral grating and (inset) cross-section of waveguide; (b) Transmittance of a FabryPerot cavity where $\Lambda=1 \mu \mathrm{m}, \mathrm{Lg}=200 \mu \mathrm{m}, \mathrm{Lc}=600 \mu \mathrm{m}, 5 \mu \mathrm{m}$ waveguide width, $4 \mu \mathrm{m}$ rib thickness and $2 \mu \mathrm{m}$ ridge thickness.

\section{References}

[1] Richard Soref, "Mid-infrared photonics in silicon and germanium", in Nature Photonics, (Macmillan Publishers Limited, 2010) pp. 495-497

[2] J.M.Ramirez et al, "Ge-rich graded-index $\mathrm{Si}_{1-\mathrm{x}} \mathrm{Ge}_{\mathrm{x}}$ waveguides with broadband tight mode confinement and flat anomalous dispersion for nonlinear mid-infrared photonics", in Optics Express, (Optical Society of America, 2017) pp. 6561-6567

[3] Vladyslav Vakarin et al, "Ultra-wideband Ge-rich silicon germanium integrated Mach Zehnder interferometer for mid infrared spectroscopy" in Optics Letters, (Optical Society of America, 2017) pp. 3482-3485.

\section{Acknowledgment:}

This project has received funding from the European Research Council (ERC) under the European Union's Horizon 2020 research and innovation programme (grant agreement N639107-INsPIRE). 